\section{Cindy Bonaparte}

Artist, Womb healing Practitioner, Social \& Environmental Arts Practice MFACandidate. I hope to expand the work of womb healing into spaces of education and learn how this collective work can advance Black peoples Liberation.

\section{Salt Water Voices: Listen between the Trauma}

Grandma said, "I dreamed of fish last night, someone's pregnant..."

Mamma said, "You have to say a prayer whenever you go to salt water, put your feet in the water. Do not go to the beach without saying a prayer before you leave, because you are at salt water."

The voices of all my mothers, conduits for the Spirits of the sea. Salt Water voices echo in my veins, the Spirits of the Waters survived weaponized Christianity, survived the confinement to double consciousness in The Souls of Black Folk*. Forced forgetting, breaks our hearts, the spiritual weapon of choice against the water souls of Black Folk. For Black folk, memory and liberation lie in our Salt Water Voices. Water holds memory of Black Folk,

water heals, water hears, water becomes

all that you say, curse, or pray

Salt purifies, heals, and repels negativity.

Your eyes cry ocean water,

Your skin sweats sea water,

All cues to tap into your power:

Your body is more ocean than land.

Your Blackness is more water than politics.

Your Black body is as sacred and healing as the waters.

Put your feet in the ocean, listen to the Salt Water Voices between the trauma when you ask:

How do we heal the breaking hearts from our collective rising blood pressure, of our salt water veins, under duress? Have we forgotten ourselves, the we are enough salt water? Are our desires, habits, likes, and taste, expres sions of the collective traumatized identity? Howe do we measure the distance of disconnection from our water) Blackness to map the roads toward liberation?

Salt Water Voices continue Black liberatory pedagogy, healing how we listen between the trauma. Salt Water Voices cleanse the pain of double consciousness and reconciles our internal waters to the power of the Ocean Mother:

*W.E.B. Dubois The Souls of Black Folk

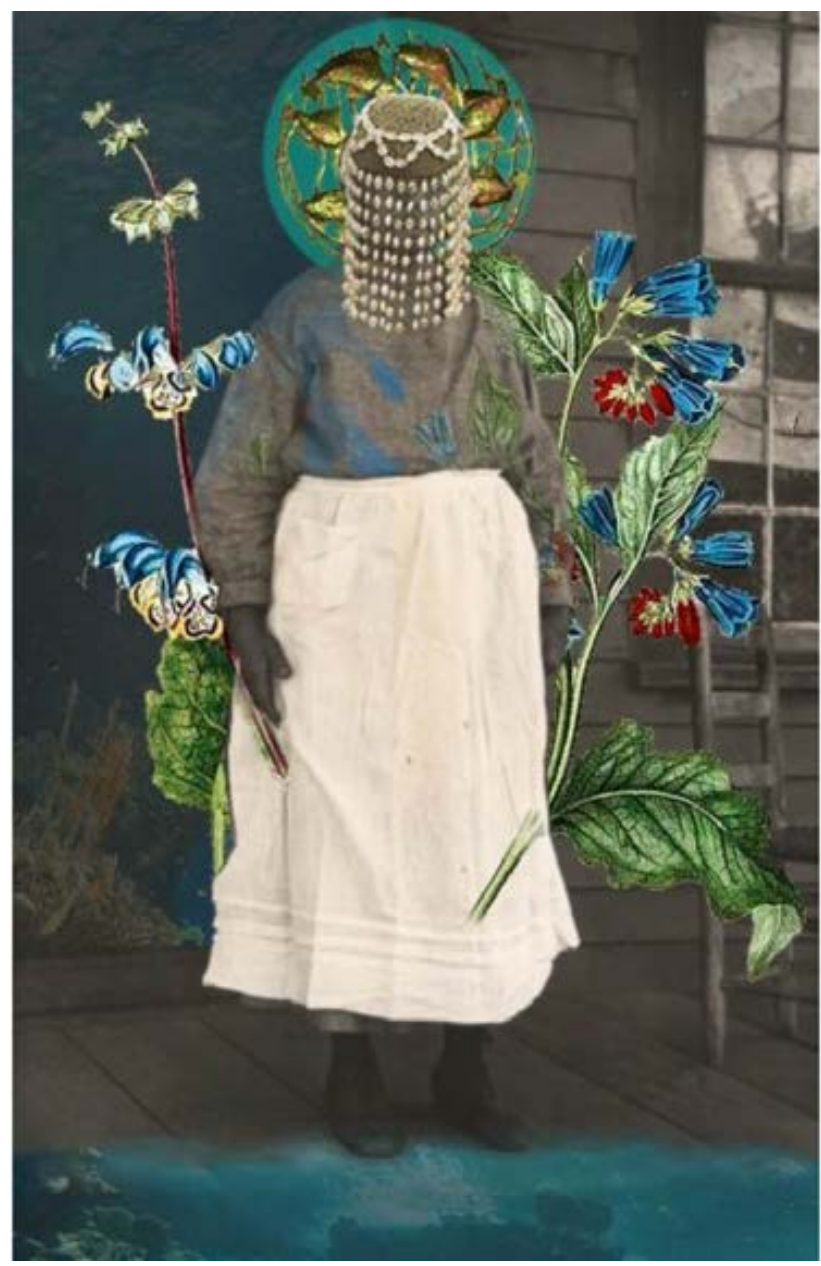

Salt Water Midwife: Aunt Dora Green \& Comfrey - 2021 - Digital Collage - Cindy Bonaparte. Source Alabama Department of Archives and History, Montgomery, Document 36.

$$
\text { Page } 31
$$

